Article

\title{
Ethics and Sustainable Management. An Empirical Modelling of Carroll's Pyramid for the Italian Landscape
}

\author{
Ernesto $D^{\prime}$ Avanzo $^{1, *(\mathbb{D}}$, Mariangela Franch ${ }^{1}$ and Elio Borgonovi ${ }^{2}$ \\ 1 Department of Economics and Management, University of Trento, 38122 Trento, Italy; \\ mariangela.franch@unitn.it \\ 2 Department of Social and Political Sciences, Bocconi University, 20100 Milano, Italy; \\ elio.borgonovi@unibocconi.it \\ * Correspondence: ernesto.davanzo@unitn.it
}

check for updates

Citation: D'Avanzo, E.; Franch, M.; Borgonovi, E. Ethics and Sustainable Management. An Empirical Modelling of Carroll's Pyramid for the Italian Landscape. Sustainability 2021, 13, 12057. https://doi.org/10.3390/ su132112057

Academic Editor: Andrea Appolloni

Received: 9 September 2021

Accepted: 27 October 2021

Published: 1 November 2021

Publisher's Note: MDPI stays neutral with regard to jurisdictional claims in published maps and institutional affiliations.

Copyright: (c) 2021 by the authors. Licensee MDPI, Basel, Switzerland. This article is an open access article distributed under the terms and conditions of the Creative Commons Attribution (CC BY) license (https:// creativecommons.org/licenses/by/ $4.0 /)$.

\begin{abstract}
Business management and, more generally, decision makers, are increasingly aware of the importance of corporate social responsibility and ethical choices within the strategic business vision. The number of tools (e.g., board of directors, organization actions), levers (e.g., cultural, social example of direct boss) and rules (e.g., protocols, certifications, law decrees) available, however, makes it difficult for management to identify the set of best practices to be adopted within its own organization. Further, the task is even more difficult when management is called upon to choose these tools for life-long learning programs intended for company staff as well as for new hires. The Italian Association for Managerial Training has promoted a survey that pays particular attention to the «ethical choices» and «behaviors» to be adopted in the organization's management and their training programs. The results of the survey have been modelled through «Carroll's conceptual framework» that, as known, is made of two parts: the most cited CSR pyramid and the least mentioned, but equally important, descriptive types of management. In this work, it has been employed a two steps multivariate analysis, employing an Exploratory Factor Analysis (EFA) and a Structural Equation Modelling (SEM). EFA has been used to identify Carroll's descriptive types (or profiles), while SEMs were employed to verify the plausibility of the causal models that represent, in turn, thought experiments simulating «ethical dilemmas» useful for the company's management during its decision making. The models identified, readable in the form of simple «heuristics», are interpreted in the light of Carroll's «descriptive types» of management (i.e., moral, immoral and amoral). Thereby, any organization, even of a small size, interested in adopting «sustainable policies», can make use of the identified models to establish which guidelines can be adopted by the management during her/his decision making, and, according to Carroll, «to isolate the ethical or moral component of CSR and relate it to perspectives that reflect the three major ethical approaches to management», with the overall objective of managing with «stakeholders in an ethical or moral fashion».
\end{abstract}

Keywords: corporate social responsibility (CSR); exploratory factor analysis (EFA); business management; ethical dilemma; sustainable policies; structural equation modelling (SEM)

\section{Introduction}

Decision makers are increasingly aware of the importance of corporate social responsibility. (CSR) and ethical choices within the strategic business vision. As for all the interdisciplinary areas, so also for the CSR there are different points of view regarding its «foundational» aspects, starting with the definition of the discipline, which changes according to the origin of the interested scholars and stakeholders [1,2]. There is a lot of scientific literature that touches on the different aspects of this field of investigation [3-9]. For instance, in the Italian landscape, it is interesting to note, among others, the work of Carlo Masini who was one of the Italian pioneers of CSR. Masini [10] insisted on the mixed character of the composition of the governing bodies of companies and, consequently, on 
the equitable distribution of the economic result among these categories (i.e., shareholders and workers). The Italian scholar considered the conception and organization of work that, according to him, should have deal with the «material and spiritual aspirations of workers».

In this context stands out the work of Carroll [11], the pyramid of social responsibility. It represents a systematic attempt trying to reorganize the «foundational» aspects of the subject, at least in the last three decades. One of the fundamental points of Carroll's paper, which appeared on Business Horizons, is precisely the vision of «pyramidal structure» according to which CSR is organized. As we will see in the next section, Carroll himself, together with Schwartz, proposed a new vision of his method [12], but which he abandoned by returning to his vision of CSR in the form of a «pyramid», because it is easily understood by management and in training programs, both at the business student level and in life-long learning programs within companies.

The Italian Association for Managerial Training (from now on ASFOR-ASFOR is the reference association dealing with management training. The ASFOR system brings together 80 associates, including the main Italian universities or Business Schools, numerous consulting and training companies as well as the Corporate Academies of large private and public groups and some professional associations. The data used in the various analyzes were given by ASFOR, in anonymous format, with the permission to process and publish the analysis based on them. All data are gathered among managers of public and private institutions associated to ASFOR network), trying to best interpret its mission of spreading the culture of entrepreneurship and business management, has promoted a survey to understand what decision-makers think, paying particular attention to the «ethical choices» and «behaviors» to be adopted in the organization's management and their training programs.

The results of the survey have been modelled through «Carroll's conceptual framework» that, as known, is made of two parts: the most cited CSR pyramid and the least mentioned, but equally important, descriptive types of management. Whereas the former represents an easy framework to understand how and why organizations should match their «social responsibilities», the latter allows the comprehension of the «management type».

Carroll's model looked suitable for the objective of this investigation, since it is shared by the scientific community and, at the same time, can be easily and intuitively used as a reference framework by decision and policy makers, both at corporate and public administration levels, as well as for training programs purposes. Some authors [13] proposed a model that supports the «heuristic» value of the pyramid, which, according to the authors, can be considered as a tool «to replace mental shortcuts», à la Simon [14], to translate complex problems into intuitive managerial actions. Meynhardt and Gomez, in their work [13], underline how it is the «heuristic value» of the pyramid that explains its popularity. Carroll's model, in fact, proves to be crucial for avoiding management from using cognitive processes to analyze complex situations, especially in conditions of uncertainty. To sum up, the authors support the thesis that the mentioned «heuristic value» represents its best justification as well.

In the research design section of this work, it has been employed a two steps multivariate analysis, employing an Exploratory Factor Analysis (EFA) and a Structural Equation Modelling (SEM). EFA has been used to identify Carroll's descriptive types (or profiles), while SEMs were employed to verify the plausibility of the causal models that represent, in turn, thought experiments simulating «ethical dilemmas» useful for the company's management during its decision making. The models identified have a «heuristic» value, as supported by [13] for the Carroll pyramid. In addition, the models identified with SEMs, readable in the form of simple «heuristics», are interpreted in the light of Carroll's «descriptive types» of management (i.e., moral, immoral and amoral). Thereby, any organization, even of a small size, interested in adopting «sustainable policies», can make use of the identified models to establish which guidelines [15] can be adopted by the management during her/his decision making.

Section 2 introduces Carroll's conceptual framework and a literature review that seeks to capture the recent debate on Carroll's model, including the positions taken by the creator 
himself. Section 3 reports on the research design, method and material adopted in this work. The research design is based on the adoption of a twofold method of multivariate analysis, that is EFA and a SEM. EFA aims at identifying the underlying relationships between measured variables, offering the opportunity of gaining an overall view of survey data. Instead, SEM allows the interpretation of three thought experiments that represent as many solutions to «ethical dilemma», which represent management beliefs in adopting ethical or unethical behaviors. It is worth remembering that, according to Carroll, the overall objective is managing with «stakeholders in an ethical or moral fashion». Section 4, reports on the results obtained from the two analyses (i.e., EFA and SEM). In particular, factors identified through the EFA are interpreted in the light of the «types» of management introduced by Carroll in his work, while SEM supports the existence of three different types of models for investigating the relationships among multiple variables, where some of them have the role of cause and others of effect. In addition to the emergence of an immoral model, two moral models emerge, one of a «deliberative nature», based on levers and tools, and the other of «regulatory nature», produced by the adoption of sustainable protocols and laws. Section 5 provide an overall discussion of the results, also in the light of current literature. Finally, Section 6 draws the conclusions of this work and, above all, its limits.

\section{Literature Review and Conceptual Background}

As known, at the bottom of the Carroll's pyramid is the concept of economic performance, what Carroll calls «be profitable». The motto of the next level of the pyramid is «obeying the law», since business is expected to represent the codification of acceptable and unacceptable behaviors of society. «Be ethical» is the third level of Carroll's pyramid and translates the obligation to do what is right; in this way it is avoided or, in any case, minimized the damage to stakeholders, whether internal or external ones. "Be a good corporate citizen» represents the highest level of the pyramid produced by the vision of the American scholar. This last concept captures the idea of "philanthropic responsibility», according to which the company is expected to provide financial and human resources to the community, contributing to improve its quality of life.

It is important to briefly mention another aspect that Carroll has developed in his work, and which is relevant to the later aims of this discussion. These are the ones that Carroll himself baptized as descriptive categories of three «types» of managers or, better, let us say management (in this context, management or manager is used, interchangeably, without wanting to alter the original meaning attributed by Carroll in his work): «immoral», «amoral» and «moral».

In the conceptual model of behavioral types proposed by Carroll [11], the «immoral manager» is the one whose decisions, actions and, in general, behaviors suggest an active opposition, one would say «deliberate», to what is considered «right» or «ethical». The main strategy adopted by «immoral management» is to exploit opportunities for personal or business gain. The second type identified by Carroll is the «amoral management», that is not sensitive to the fact that his daily business decisions can have detrimental effects on others, thus lacking completely ethical perception or awareness. The third profile traced by Carroll is the «moral management» which employs ethical norms that respect a high standard of behavior. For instance, when an ethical dilemma arises, the «moral manager» succeeds in assuming a leadership position for his company or organization [16-18] and are examples of leadership when ethical issues arise [19]. Carroll, in his seminal work, points out that the "goal is to accentuate the moral management approach by contrasting it with the other two types» [11].

Meynhardt and Gomez [13] emphasize that Carroll's remains the best model of CSR, despite the various attempts to resize the pyramid or attempts to replace it, such as that by its own creator, Archie Carroll that, in 2003, together with his co-author, Mark S. Schwartz, proposed a new approach [12]. Schwartz and Carroll have adopted Venn diagrams as a model to depict domains of economic, legal, and ethical responsibilities in a unique overall framework. In their work the authors suggested corporate examples classified according 
to the new model. The model developed by Schwartz and Carroll, however, did not have the same success as the pyramid, which, on the other hand, proved to be strategic not only for management, but, above all, for educational purposes, as he rightly points out [20].

In her work [20], Denise Baden proposes a re-dimensioning of the order proposed by Carroll's pyramid model, in the light of a new vision, more "socially responsible», which, in her opinion, must adopt business practitioners and business students. In particular, the author of the work questions the primacy of «economic responsibility» at the base of the pyramid. Referring to moral conceptual arguments and empirical findings, the author argues that Carroll's pyramid does not represent real-life models of «social responsibility» and proposes a re-ordered pyramid, placing ethical responsibilities at its base, followed by legal ones, then economic responsibilities and, finally, philanthropic responsibilities.

In his work [21], Masoud proposed «the international pyramid model of CSR» introducing two attempts of innovation with respect to the original pyramid. The first attempt is represented by the introduction of the «glocal responsibilities» (i.e., global + local), aiming at linking environment, socio cultural matters, technology users, and political rights. The second attempt is represented by the merging of legal and ethical responsibilities into one level of obligation. With the introduction of «glocal responsibilities», the explicit goal of the author is to support «CSR activities to the wider population of the country concerned, and even beyond that to the global community as a means of identifying worthwhile social goals and remedying social concerns».

Jintao et al. [22] analyzed Carroll's pyramid, in the small-medium enterprises (SMEs) context, with the aim of proving the usefulness of an updated pyramid model as business strategy for organizational performance of Industry 4.0 advance. The new pyramid contemplates «organizational innovation» as a mediator and «corporate image» as a moderator. Results show that the new conceptual model has positive implications for the organizational performance of the SMEs, which, according to the author, should adopt the Industry 4.0 concept to take ethical, ecological and economic advantages. The experiments also show that the economic and ethical components are of crucial importance for SME's performance. Overall, the work suggests CSR activities to the senior management of the SMEs in order to add a green «corporate image» by adopting an environmental component in Carroll's pyramid.

In a review article [23], published in 2016, Archie Carroll put the emphasis on some features of his model, which, according to the author, were not highlighted in his seminal work appeared on Business Horizon. For instance, Carroll emphasizes the «global applicability» of his model and its value for «use in different contexts». As regards the former point, Carroll takes up the theses outlined by Visser in his work [24], according to which «each region, country or community has a different set of drivers of CSR». Further, Carroll still shares Vissen's view when he argues that among the most important «glocal $($ global + local) drivers of CSR», a chief role is played by «cultural tradition», "political reform», «socio-economic priorities», «governance gaps», and «crisis response». As for the latter aspect (i.e., the use of the pyramid in different contexts), the American scholar argues that some contexts of potential interest «include private sector (large vs. small firms), public sector, and civil society organization.

Two important aspects taken up by Carroll in this work are the "pyramid shape» of its model and the concept of «sustainability». Regarding the first aspect, Carroll argues that «the pyramid was selected as a geometric design because it is simple, intuitive, and built to withstand the test of time». As regards the concept of sustainability, Carroll supports the thesis that «the pyramid should be seen as sustainable in that these responsibilities represent long term obligations that overarch into future generations of stakeholders as well». In other words, for Archie Carroll, the pyramid is «intended to be seen as a dynamic, adaptable framework the content of which focuses both on the present and the future».

As can be seen from the short survey of the literature above, by no means exhaustive, the works reviewed represent attempts in which, overall, it has been proposed to change the priority of the levels of Carroll's pyramid, arguing now in favor of one now of the other 
level at the base of the pyramid. For example, the primacy of economic responsibility has been questioned by many authors. Others have highlighted the importance of the primacy of ethical responsibilities. Carroll, however, supports that the concept of «ethics» permeates its pyramid [23].

In the following sections of our work, the levels of responsibility of Carroll's pyramid are not questioned, given the remarkable success that the pyramid model is also enjoying in the eyes of its detractors. As seen above, some attempts have done nothing but look for a solution within the Carroll paradigm, perhaps moving the different levels of responsibility «up and down the pyramid», to testify the recognition and validity of the Carroll's model.

Another reason led us to keep Carroll's original approach, that is, the "descriptive categories» of management [11], through which Carroll aims «to isolate the ethical or moral component of CSR and relate it to perspectives that reflect the three major ethical approaches to management», with the overall objective of managing with "stakeholders in an ethical or moral fashion» [11] (p. 39). To this end the experiments performed in the following represent an attempt to empirically identify Carroll's types, from scratch, employing local drivers and levers, as suggested the literature reviewed above.

Last, but not least, the models identified in the following of this work, and interpreted in the light of Carroll's «descriptive types» of management, are readable in the form of simple «heuristics», as supported by [13], and in the light of Carroll pyramid.

\section{Material and Methods}

The overall objective of the following two-step-analysis is «to isolate the ethical or moral component of CSR» and playing with some scenarios to verify the managing with «stakeholders in an ethical or moral fashion», as imagined by Carroll in his work [11].

A sustainable corporate management model is based on ethical decisions. To better understand in which way business responsible behaviors are associated to ethics, participants into a survey were asked to indicate the degree of consistency between «ethics» and types of business responsibility suggested by Carroll's pyramid.

The dataset coming from survey, and run among Italian managers, during the first two weeks of May 2018, is made of 157 observations, described by 72 variables. During the pre-processing step, 5 variables have been deleted because they were incomplete and with noise, so the final number of variables amounts to 67 . The answers were given on a Likert scale from 1 to 7 , in which 7 represents the highest degree of adhesion between «ethics» and related concepts.

The method for analyzing data employed is made of two steps: an Exploratory Factor Analysis (EFA) and a Structural Equation Modelling (SEM). EFA has been used to identify Carroll's descriptive types of management, while SEM was employed to investigate the relationships among factors identified in the first step.

First analysis-EFA analysis allows the identification of new factors which are common to the variables collected through the survey. EFA aims at identifying the underlying relationships between measured variables [25], offering the opportunity of gaining an overall view of the data. The output can be employed in subsequent analyses [26,27], as in the following Section 4, to understand how some of the factors identified are related each other's through some kinds of «causal relations».

The literature supports that the ideal number of factors to consider should correspond to the number of positive eigenvalues of the correlation matrix [28,29], even if some useful rule of thumbs [30] suggest keeping only those factors whose eigenvalues are greater than 1. Another important issue to be considered emerges when it is time to interpret and naming the extracted factors, on the basis of their factor loadings. A body of knowledge [31-33] suggests the adoption of factor rotation because it alters the pattern of the factor loadings and, as a consequence, can improve the overall interpretation of the model proposed.

In order of interpreting factors, EFA asks for the employment of the pattern matrix that allows the inspection of pattern loadings (i.e., regression coefficients of variables on factors). Table 1 shows the pattern matrix of the final EFA described in the following. 
Reference [34] suggests the employment of factor loadings whose absolute values are greater than 0.4 ; in other words, this rule allows to identify only those factors able to explain about $16 \%$ of variance.

Table 1. The table contains the complete list of the 13 factors returned by EFA, and the corresponding factor loadings.

\begin{tabular}{|c|c|c|c|c|}
\hline & Observed Variable/Item Name & Code & \# of Items & Factor Loadings \\
\hline \multirow{7}{*}{$\begin{array}{l}\text { Factor } 1 \\
\text { Professional ethics } \\
\text { perception } \\
\text { (Moral profile) }\end{array}$} & $\begin{array}{l}\text { Degree of coincidence/coherence of the concept of ethics with } \\
\text { the nouns proposed-Correctness }\end{array}$ & V55 & 39 & 0.83 \\
\hline & $\begin{array}{l}\text { Degree of coincidence/coherence of the concept of ethics with } \\
\text { the nouns proposed-Morality }\end{array}$ & V56 & 40 & 0.82 \\
\hline & $\begin{array}{l}\text { Degree of coincidence/coherence of the concept of ethics with } \\
\text { the nouns proposed-Legality }\end{array}$ & V53 & 37 & 0.79 \\
\hline & $\begin{array}{l}\text { Degree of coincidence/coherence of the concept of ethics with } \\
\text { the nouns proposed-Impartiality }\end{array}$ & V58 & 42 & 0.79 \\
\hline & $\begin{array}{l}\text { Degree of coincidence/coherence of the concept of ethics with } \\
\text { the nouns proposed-Justice }\end{array}$ & V57 & 41 & 0.76 \\
\hline & $\begin{array}{c}\text { Degree of coincidence/coherence of the concept of ethics with } \\
\text { the nouns proposed-Legality }\end{array}$ & V54 & 38 & 0.76 \\
\hline & $\begin{array}{c}\text { Degree of coincidence/coherence of the concept of ethics with } \\
\text { the nouns proposed-Meritocracy }\end{array}$ & V59 & 43 & 0.74 \\
\hline \multirow{6}{*}{$\begin{array}{l}\text { Factor } 2 \\
\text { Ethical dilemma } \\
\text { (Immoral profile) }\end{array}$} & $\begin{array}{c}\text { Keep the secret of known pollution effects for reasons of } \\
\text { competitiveness, knowing however that there may be risks (not } \\
\text { certainties) for the health of workers and/or inhabitants, to } \\
\text { safeguard the survival of the company and the work of its } \\
\text { employees }\end{array}$ & V44 & 30 & 0.85 \\
\hline & $\begin{array}{l}\text { Finding formally correct ways to get bribes or other forms of } \\
\text { corruption to avoid the risk of bankruptcy of } \\
\text { companies/organizations or to dismiss a significant number of } \\
\text { employees (e.g., over 50\%) }\end{array}$ & V35 & 21 & 0.77 \\
\hline & $\begin{array}{c}\text { In order not to pay back debts (e.g., debts to suppliers, debts to } \\
\text { the tax authorities) decide to plan the bankruptcy of the } \\
\text { company and then establish another }\end{array}$ & $\mathrm{V} 40$ & 26 & 0.69 \\
\hline & $\begin{array}{l}\text { Keep the secret on known pollution effects, which however have } \\
\text { no direct impact on the health of workers and inhabitants, to } \\
\text { safeguard the survival of the company and the work of its } \\
\text { employees for reasons of competitiveness }\end{array}$ & V43 & 29 & 0.68 \\
\hline & $\begin{array}{c}\text { Finding formally correct ways to get bribes or implement other } \\
\text { forms of corruption at international level when it is considered } \\
\text { that this is the general practice }\end{array}$ & $\mathrm{V} 42$ & 28 & 0.65 \\
\hline & $\begin{array}{l}\text { Do not punish/sanction the behaviors of collaborators who have } \\
\text { violated ethical rules not for their own interests but to bring } \\
\text { more profits to the company }\end{array}$ & V37 & 23 & 0.62 \\
\hline \multirow[t]{2}{*}{$\begin{array}{l}\text { Factor } 3 \\
\text { Culture, reputation } \\
\text { and leadership } \\
\text { (Moral profile) }\end{array}$} & $\begin{array}{l}\text { Optimize/maximize results, given certain constraints, such as } \\
\text { market constraints, competition for companies, laws and policy } \\
\text { choices in public administrations, resources available from } \\
\text { donations and contributions for non-profit institutions, etc. }\end{array}$ & V73 & 44 & 0.75 \\
\hline & Board of directors & V75 & 46 & 0.66 \\
\hline
\end{tabular}


Table 1. Cont.

\begin{tabular}{|c|c|c|c|c|}
\hline \multirow{4}{*}{$\begin{array}{l}\text { Factor } 4 \\
\text { Levers for ethical } \\
\text { behaviors } \\
\text { (Moral profile) }\end{array}$} & The example of the behavior of direct boss & V84 & 52 & 0.92 \\
\hline & Social network & V82 & 51 & 0.76 \\
\hline & The spread of markedly corporate culture & V87 & 54 & 0.56 \\
\hline & Organizational actions to spread the culture of ethics & V85 & 53 & 0.46 \\
\hline \multirow{4}{*}{$\begin{array}{l}\text { Factor } 5 \\
\text { Sustainable policies } \\
\text { For management } \\
\text { (Moral profile) }\end{array}$} & Application of laws/guidelines anti-corruption protocols & V77 & 48 & 0.69 \\
\hline & Ethical certification SA 8000 & V78 & 49 & 0.61 \\
\hline & $\begin{array}{l}\text { Social balance sheet, social impact indicators and other CSR } \\
\text { instruments }\end{array}$ & V79 & 50 & 0.57 \\
\hline & $\begin{array}{l}\text { Specifically, the D.L. } 231 / 2011 \text { on corporate responsibility and } \\
\text { 190/2012 for public administrations }\end{array}$ & V76 & 47 & 0.56 \\
\hline \multirow{2}{*}{$\begin{array}{l}\text { Factor } 6 \\
\text { Lobbying as } \\
\text { responsible activity } \\
\text { (Moral profile) }\end{array}$} & $\begin{array}{l}\text { The lobbying activity would not in itself be negative when } \\
\text { regulated and made transparent }\end{array}$ & V32 & 19 & 0.88 \\
\hline & $\begin{array}{l}\text { The regulated and transparent lobbying activity can be positive } \\
\text { because, on complex problems, it brings to the attention both of } \\
\text { those who decide public policies and of the interests of different } \\
\text { stakeholders who can balance each other }\end{array}$ & V31 & 9 & 0.79 \\
\hline \multirow{3}{*}{$\begin{array}{c}\text { Factor } 7 \\
\text { Management } \\
\text { awareness of bad } \\
\text { practices } \\
\text { (Moral profile) }\end{array}$} & $\begin{array}{l}\text { The diffusion of the ethical sense depends mainly on the culture } \\
\text { of the countries }\end{array}$ & V19 & 9 & 0.76 \\
\hline & $\begin{array}{l}\text { The phenomenon of bribery-corruption is mainly linked to the } \\
\text { culture of a country and is not strictly economic }\end{array}$ & V28 & 17 & 0.72 \\
\hline & $\begin{array}{c}\text { The diffusion of the ethical sense depends mainly on the } \\
\text { individual values of people }\end{array}$ & V18 & 8 & 0.46 \\
\hline \multirow{3}{*}{$\begin{array}{c}\text { Factor } 8 \\
\text { Management } \\
\text { awareness of bad } \\
\text { practice } \\
\text { (Immoral profile) }\end{array}$} & $\begin{array}{l}\text { In Italy the corruption-bribery phenomenon is a widespread } \\
\text { practice to obtain advantages in the relationships between } \\
\text { companies (in general private subjects) and public administrations } \\
\text { (tenders, supplies, concessions, authorizations, etc.) }\end{array}$ & V24 & 13 & 0.61 \\
\hline & $\begin{array}{l}\text { There has been a lot of talk in Italy in recent years but little has } \\
\text { been done to combat corruption-bribery }\end{array}$ & V26 & 15 & 0.60 \\
\hline & $\begin{array}{l}\text { The debate on ethics is mainly of image and facade, often used } \\
\text { in an instrumental way and does not substantially touch the real } \\
\text { behavior of companies/organizations }\end{array}$ & V8 & 1 & 0.52 \\
\hline \multirow{4}{*}{$\begin{array}{l}\text { Factor } 9 \\
\text { Personal ethical } \\
\text { perception } \\
\text { (Moral profile) }\end{array}$} & $\begin{array}{l}\text { Indicate the degree of coincidence/coherence of the "ethical" } \\
\text { concept with the proposed nouns, } \\
\text { according to your own conception-Impartiality }\end{array}$ & V50 & 35 & 0.73 \\
\hline & $\begin{array}{l}\text { Indicate the degree of coincidence/coherence of the "ethical" } \\
\text { concept with the proposed nouns, } \\
\text { according to your own conception-Justice }\end{array}$ & V49 & 34 & 0.65 \\
\hline & $\begin{array}{l}\text { Indicate the degree of coincidence/coherence of the "ethical" } \\
\text { concept with the proposed nouns, } \\
\text { according to your own conception-Meritocracy }\end{array}$ & V51 & 36 & 0.57 \\
\hline & $\begin{array}{l}\text { Indicate the degree of coincidence/coherence of the "ethical" } \\
\text { concept with the proposed nouns, } \\
\text { according to your own conception-Correctness }\end{array}$ & V47 & 33 & 0.42 \\
\hline \multirow{4}{*}{$\begin{array}{l}\text { Factor } 10 \\
\text { Ethical dilemma } \\
\text { (Moral profile) }\end{array}$} & $\begin{array}{l}\text { Look for new markets to abandon markets that are recognized } \\
\text { as ethically compromised even if they are at a high profit }\end{array}$ & V41 & 27 & 0.57 \\
\hline & Apply safeguards to reconcile work/family actions & V38 & 24 & 0.56 \\
\hline & Choose not to withhold earnings to avoid laying off some employees & V36 & 22 & 0.45 \\
\hline & $\begin{array}{l}\text { Support higher costs for environmental prevention and land } \\
\text { conservation, even when it is not mandatory by law }\end{array}$ & V39 & 25 & 0.43 \\
\hline
\end{tabular}


Table 1. Cont.

\begin{tabular}{|c|c|c|c|c|}
\hline \multirow{2}{*}{$\begin{array}{l}\text { Factor } 11 \\
\text { Desire of clear rules } \\
\text { (Moral profile) }\end{array}$} & In all sectors the presence of clear rules favors ethical behaviors & V20 & 10 & 0.77 \\
\hline & $\begin{array}{l}\text { The difficulties of adopting ethical behavior depend on the lack } \\
\text { of clear and transparent rules }\end{array}$ & V16 & 7 & 0.57 \\
\hline \multirow{2}{*}{$\begin{array}{l}\text { Factor } 12 \\
\text { Desire of clear rules } \\
\text { (Moral profile) }\end{array}$} & $\begin{array}{l}\text { The crisis has positively influenced the adoption of ethical } \\
\text { behaviors }\end{array}$ & V23 & 12 & 0.78 \\
\hline & $\begin{array}{l}\text { The adoption of ethical behavior was negatively affected by the } \\
\text { recent crisis }\end{array}$ & V14 & 6 & -46 \\
\hline \multirow{3}{*}{$\begin{array}{l}\text { Factor } 13 \\
\text { Perception of Ethics } \\
\text { for-profit and } \\
\text { non-profit }\end{array}$} & $\begin{array}{l}\text { In Italy the corruption-bribery phenomenon is a widespread } \\
\text { practice in relations between private individuals/companies } \\
\text { (companies' supply chains, credit concessions by banks, etc.) }\end{array}$ & V25 & 14 & 0.50 \\
\hline & $\begin{array}{l}\text { In the public sector, on average, there is a higher ethical sense } \\
\text { than in the private sector }\end{array}$ & V22 & 11 & 0.43 \\
\hline & $\begin{array}{c}\text { The ethical sense is stronger in the non-profit sector compared to } \\
\text { for-profit companies }\end{array}$ & V13 & 5 & 0.41 \\
\hline
\end{tabular}

To establish the number of factors that can summarize data, it has been employed the Very Simple Structure procedure (VSS) that applies a goodness of fit test to determine the optimal number of factors to be extracted [35]. VSS achieves a maximum of 0.63 with 12 factors (with a fit of 0.85 and RMSEA of 0.065), even if parallel analysis suggests that the number of factors should be 10, as can be seen looking at Figure 1.

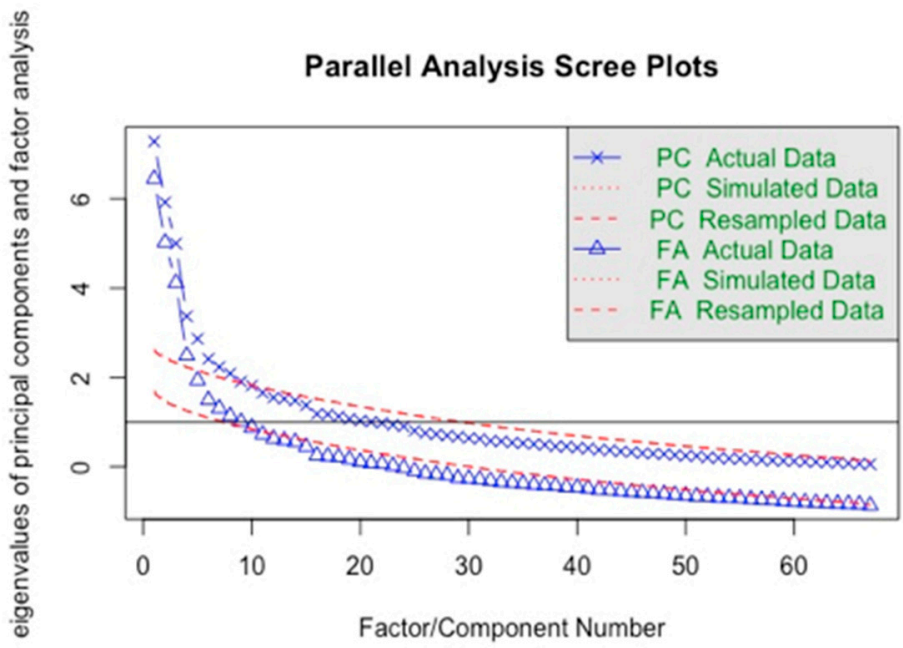

Figure 1. Parallel analysis suggests that the number of factors should be 10. Eigenvalues range.

Second analysis-Even if EFA is a useful methodology to identify factors representing the "profiles» of Carroll's conceptual framework, it does not offer a view on how factors are related each other's, a job that is proposed in the following by employing causal models, an approach for investigating the relationships among multiple variables, where some of them have the role of cause and others of effect [36].

The causal models employed in the following are based on structural equation modelling (SEM). As known, when employing SEM, the relationships between the constructs constitute the so-called structural model, which, together with the measurement model, generated by the relationships between indicators and constructs, generates the SEM. As for the structural model, for instance, the arrow that starts from the construct «immoral management», the cause, is directed towards the construct «ethical dilemma», that is the effect.

The first model, discussed in Section 4 represents a thought experiment where the «immoral management» construct causes questionable managerial choices, as demonstrated 
by the solution to «ethical dilemma», which represents a general belief of the management in adopting unethical behaviors when these are believed useful for the company.

The second model, discussed in Section 4, is twofold because it is represented by two thought experiments, aiming to investigate what levers and tools were useful for guiding ethical choices by management. Indeed, as supported by Carroll in his work [11], that support the overall objective of managing with «stakeholders in an ethical or moral fashion».

\section{Results}

Results from first analysis-Factors identified through the EFA are interpreted in the light of the «types» of management introduced by Carroll in his work [11]. In this context, the term «profile» is used synonymously with «type», as proposed by the American scholar (briefly, we mean by «profile» the result of the quantitative analysis of the features of an organization or of a person who interacts with that organization). The complete list of the 13 factors returned by EFA, and the corresponding factor loadings, are shown in the Table 1. The table also contains a code/identifier for each variable/response that is employed for any further analysis carried out in this work.

The profile «reflected in» factor 1, and represented in Figure 2, is interpretable as a general attitude towards ethical behaviors and characterized by «morality», «legality», «justice», «meritocracy» and so on. A management characterized by this profile is certainly located in the intermediate part of Carroll's pyramid, distinguished by the motto «be ethical».

Factor 2, represented in Figure 3, seems to express a general intention of the subject in adopting unethical behaviors when he believes that it could be useful for his company.

As mentioned in Section 2, this management profile is primarily concerned with the profitability and success of its organization that, on the whole, induces the management interpreting the legality standards as barriers or impediments to overcome, in order to achieve its own goals.

Variables «reflected in» factor 2 a conflict of values, where the manager is required to take a decision, such as in «keep the secret of known pollution effects for reasons of competitiveness $[\ldots]$ ]».

Factor 3, as can be observed in Table 1, is characterized by an overall attitude towards reputation and leadership. Indeed, the first variable where factor 3 is «reflected in» contemplates an «optimization among market constraints, competition, laws and policy choices in public administrations, resources available from donations and contributions for non-profit institutions", indicating an overall reputation tool, while the second variable represents a leadership tool, that is the «board of directors».

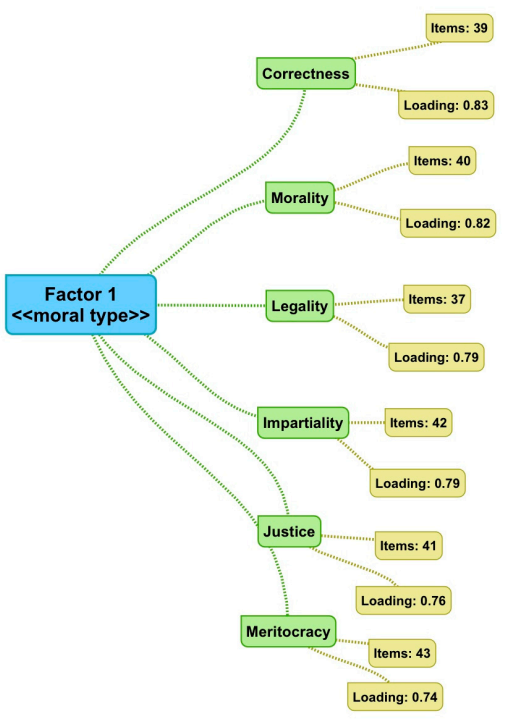

Figure 2. «Moral management» profile represented by factor 1 . 


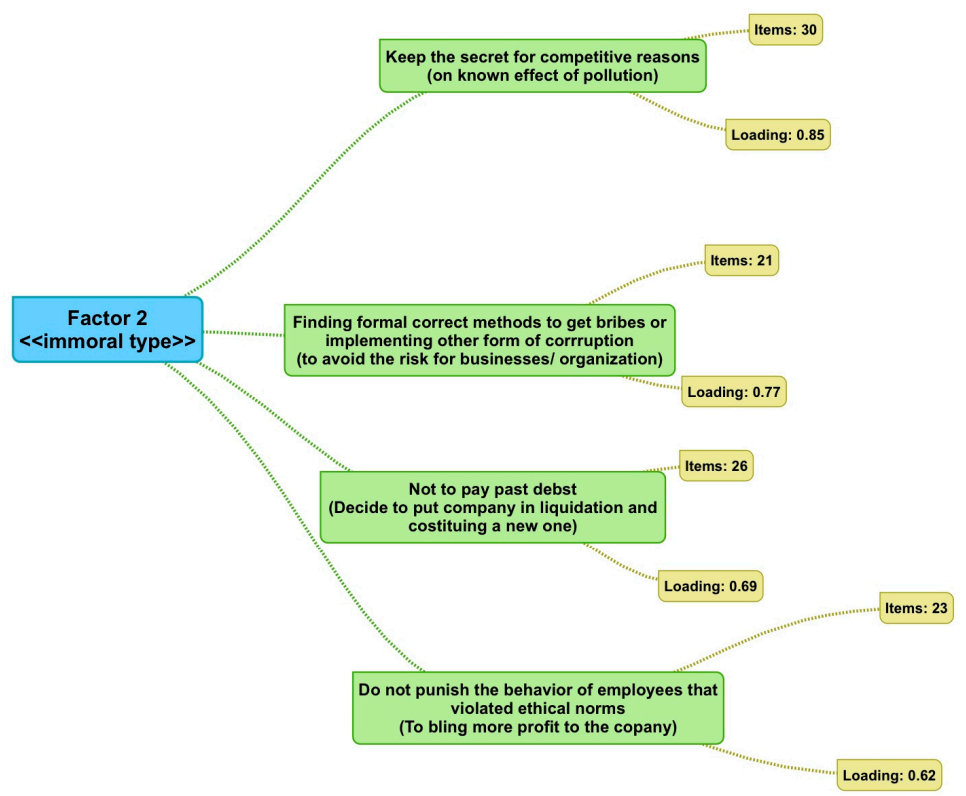

Figure 3. «Immoral management» profile represented by factor 2 (ethical dilemmas).

Factor 4, as represented in Figure 4, indicates the levers that are considered to be effective in order to spread or strengthen ethical behaviors. Indeed, the most important variable/response is «the example of direct leader behavior» which still represents a request for leadership.

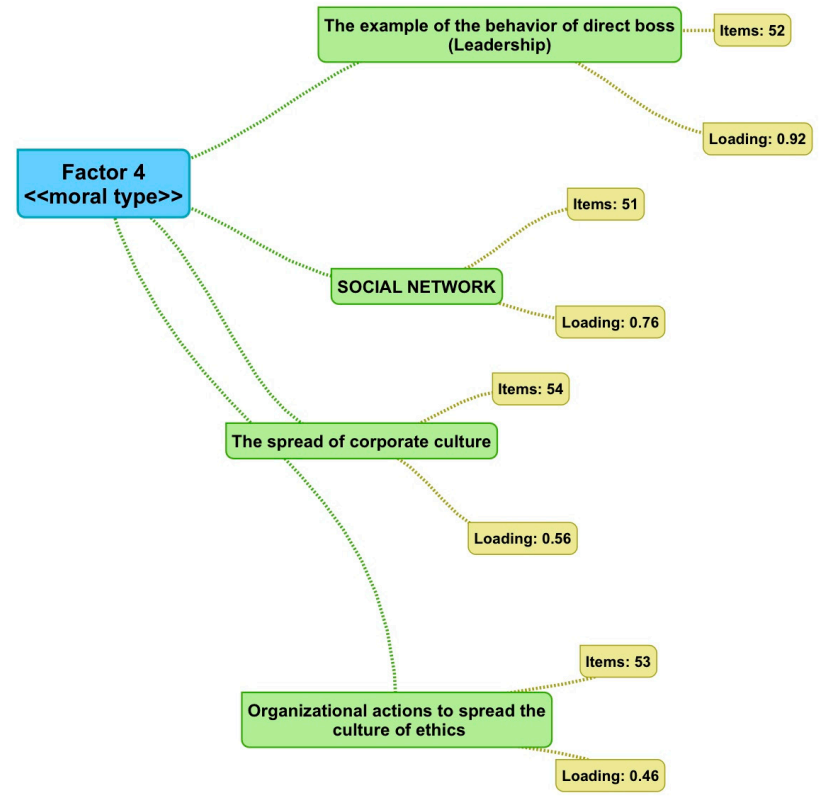

Figure 4. «Moral management» profile represented by factor 4 .

Figure 5 shows factor 5 that indicates a general intention/desire to develop «legislative measures» or, in any case, «ethical rules/norms» that can be used in the management of an organization. Variables represent CSR and sustainability policies such as the «ethical certification SA 8000», or "anti-corruption protocols», that are perceived as effective tools that companies, and organizations, can adopt to spread or strengthen ethical behaviors. 


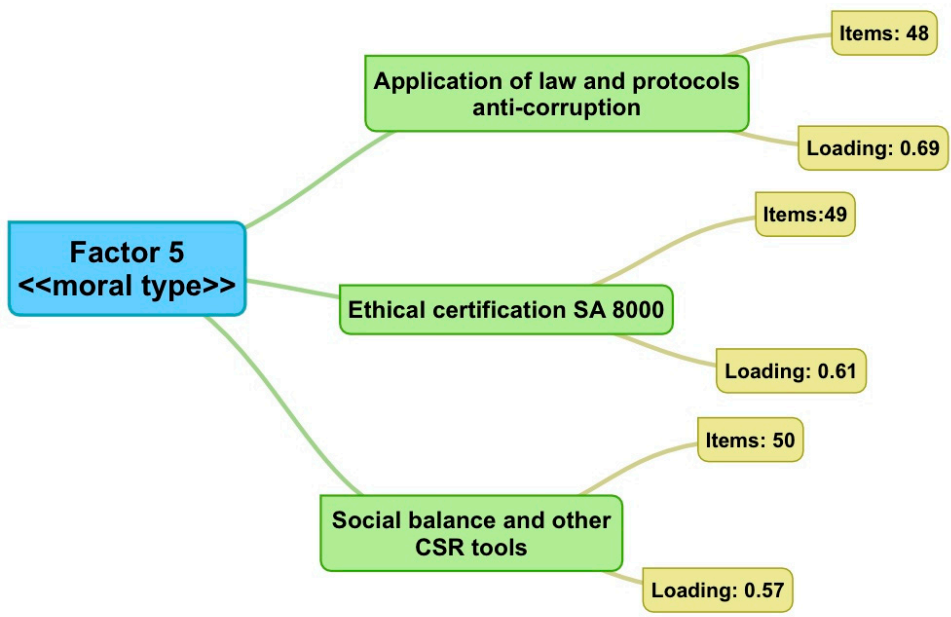

Figure 5. «Moral management» profile represented by factor 5 .

Factor 6, which gives rise to a variable such as «the lobbying activity would not in itself be negative when regulated and made transparent» in line with [37], which supported that «business lobbying is a socially responsible activity» to institutionally regulate external relations between companies.

Factor 7, depicted in Figure 6, identifies the perception of the ethical sense diffusion in the various sectors such as those depending on «the culture of the country» and/or «individual values of people».

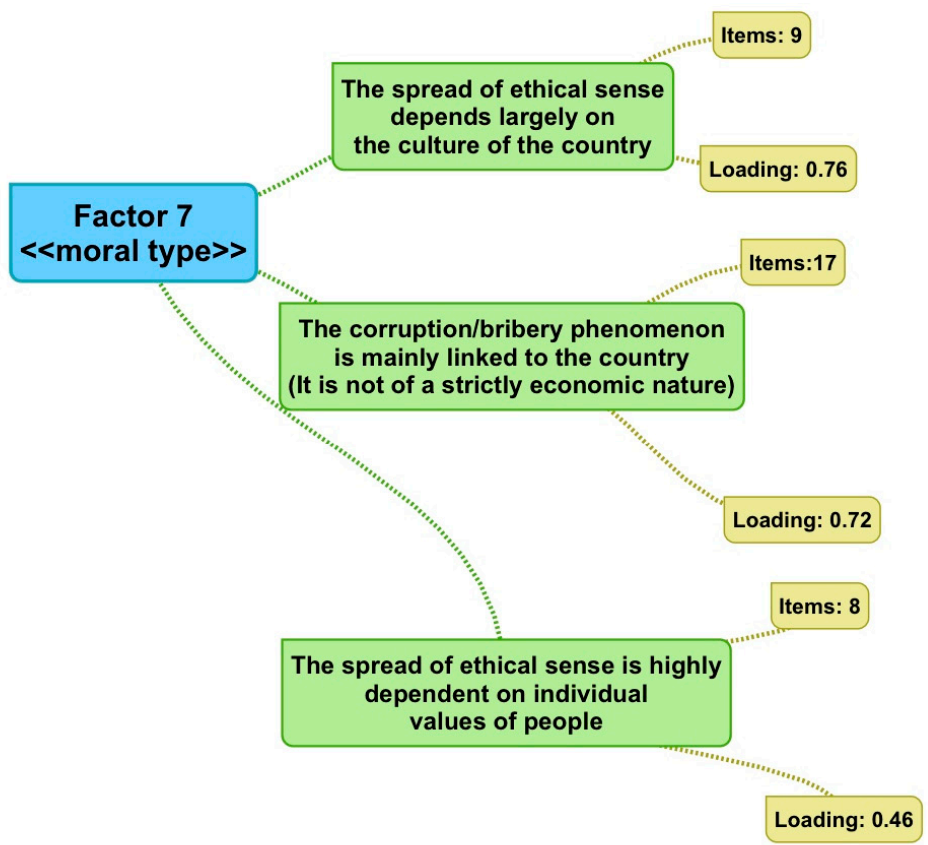

Figure 6. «Moral management» profile represented by factor 7 .

Variables/responses that contribute to «construct» factor 8, represented in Figure 7, also make explicit reference to the phenomenon of «corruption» as a practice in Italy «to obtain advantages in relationships where players are companies and public administration». Another variable/answer belonging to factor 8 (see Table 1) supports that «there has been a lot of talk in Italy in recent years, but little has been done to combat corruption-bribery». 


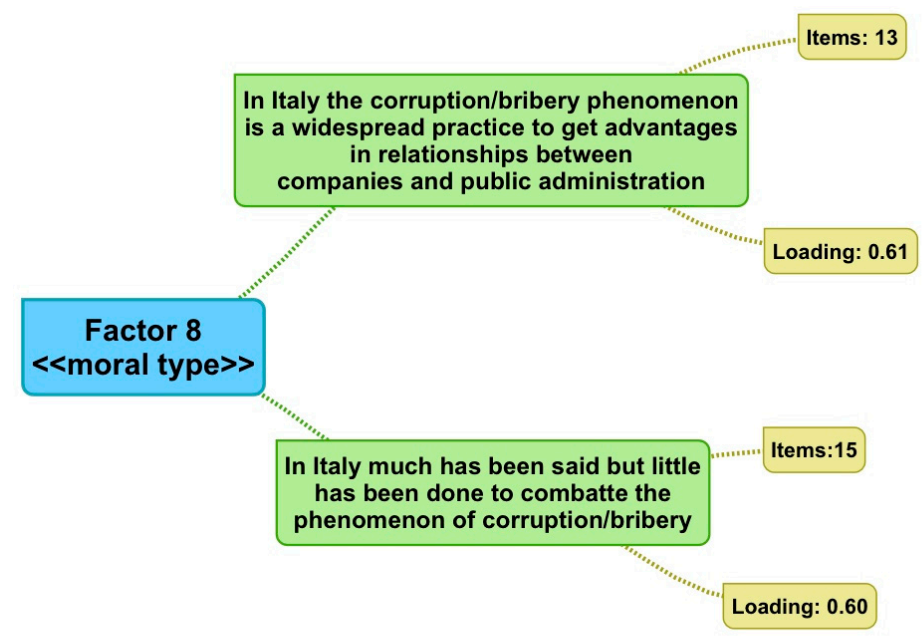

Figure 7. «Moral management» profile represented by factor 8 .

Factor 9 relates terms (i.e., synonyms or correlates), which describe the concept of ethics (e.g., impartiality, justice, meritocracy and so on) as perceived by the managers interviewed, unlike the same terms grouped by factor 1, which instead refer to the professional environment.

Factor 10 gives rise to variables/answers that represent another battery of ethical dilemmas such as «look for new markets to abandon markets that are recognized as ethically compromised even if they are at a high profit».

The desire for «clear rules» to be adopted are also represented by factor 11, while from factor 12 it emerges that the economic crisis represented a stimulus to adopt ethical behaviors in the management of companies and organizations.

Finally, factor 13 also shows that the ethical sense is perceived stronger in the non-profit sector compared to for-profit companies.

Results from second analysis-in the first model, represented in Figure 8, an «immoral management» construct is «reflected in» five indicators (i.e., variable/responses): V24, V25, $V 26$ and $V 28$.

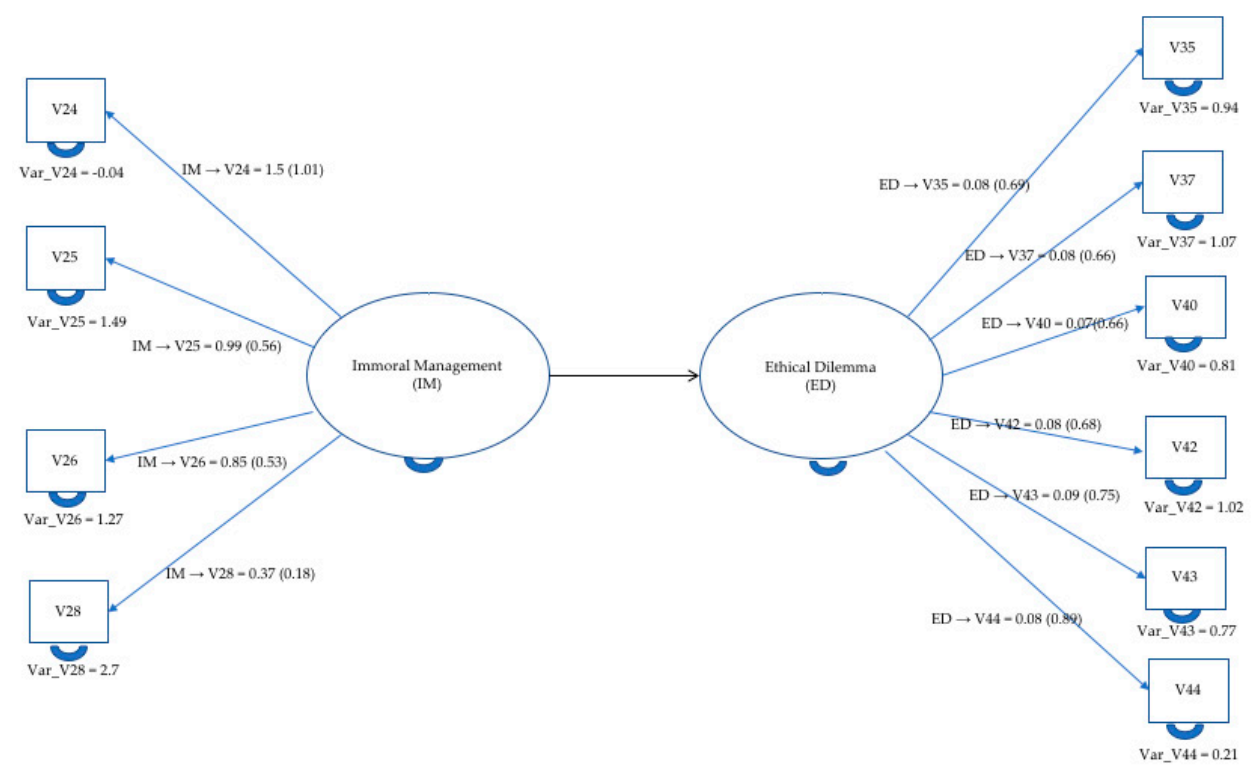

Figure 8. The first SEM model «explains» the relationship among the triggered «immoral management» construct (IM) and the «ethical dilemma» construct (ED).

As can be seen in Table 1, all variables reflecting in this construct represent the perception of ethics (V24 and V26) on a social (V25), and cultural (V28) basis, as discussed in EFA above. The construct «immoral management» causes questionable managerial choices, as 
demonstrated by the solution of «ethical dilemma» that is triggered, in turn, by variables $V 35, V 37, V 40, V 42, V 43, V 44$. In fact, all such indicators belong to the factor 2, identified by EFA above, which represents a general belief of the management in adopting unethical behaviors when these are believed useful for the company (e.g., V44).

Table 2 reports analytical results demonstrating the «goodness of the model» and its reasonability to explain the causal relationship among «immoral management» and «ethical dilemma» constructs, with the former is significant to explain the latter.

Table 2. The table reports the goodness of the model represented in Figure 8. For each index, the corresponding reference scores (good and acceptable) is reported.

\begin{tabular}{cccc}
\hline Fit Index & Score & \multicolumn{2}{c}{ Reference Scores } \\
\hline & & Good & Acceptable \\
\hline$\chi^{2} / \mathrm{df}$ & 0.920 & $0 \leq \chi^{2} / \mathrm{df} \leq 2$ & $2 \leq \chi^{2} / \mathrm{df} \leq 3$ \\
CFI (Comparative fit index) & 0.988 & $0.97 \leq \mathrm{NFI} \leq 1.00$ & $0.95 \leq \mathrm{NFI} \leq 0.97$ \\
TLI (The Tucker-Lewis coefficient) & 0.984 & As close as possible to 1 & \\
RMSEA (Root mean square error of & 0.034 & $0 \leq$ RMSEA $\leq 0.05$ & $0.05 \leq$ RMSEA $\leq 0.10$ \\
approximation) & & &
\end{tabular}

The solution of the «ethical dilemma» represented in the model of Figure 8, if read in terms of Carroll's conceptual framework, it belongs to the lowest level of the pyramid, the one distinguished by the economic performance, what Carroll calls «be profitable».

Since during the administration of the questionnaire, the managers interviewed were asked to indicate, in their opinion, what was the effectiveness of some «levers» and «tools» in spreading or strengthening ethical behaviors, then two other thought experiments were introduced aiming to investigate what levers and tools were useful for guiding ethical choices by management. Indeed, as supported by Carroll in his work [11], the overall objective is managing with «stakeholders in an ethical or moral fashion» [11] (p. 39).

The two simulations have been performed employing the causal models represented in Figures 9 and 10, both referring to the same «ethical dilemma», that is the one «reflected in» the indicators $V 36, V 38, V 39$, and $V 41$. A high degree of adherence with the indicators of this factor can be interpreted as an attitude towards a «moral management» profile, the highest of Carroll's pyramid, that captures the idea of philanthropic responsibility.

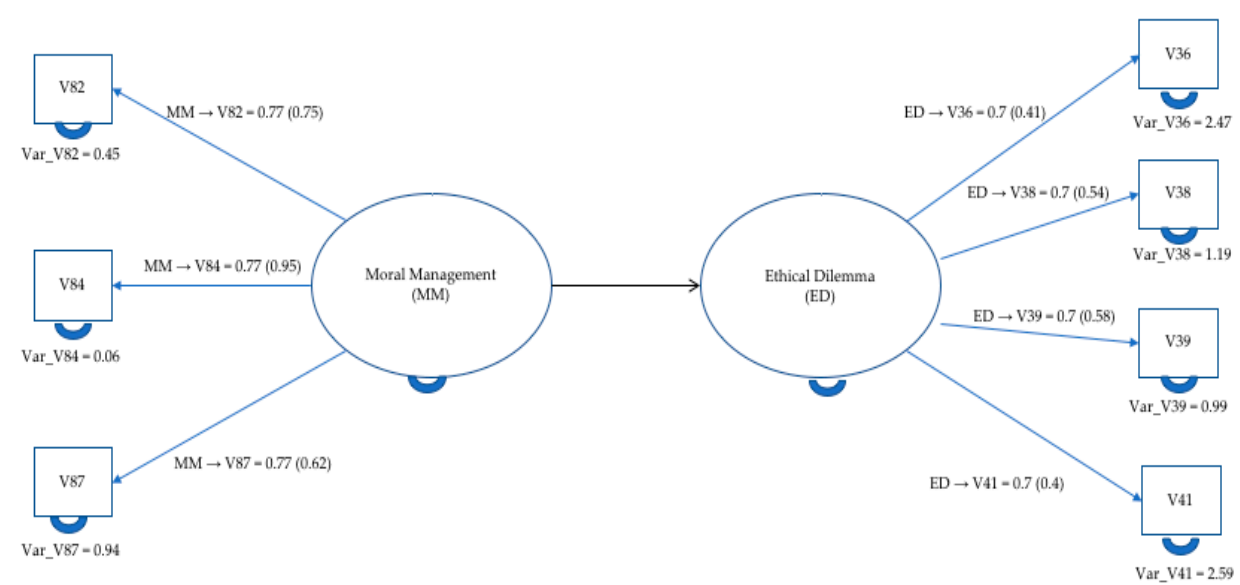

Figure 9. The second SEM model «explains» the relationship among the triggered «moral management» construct (MM) and the «ethical dilemma» construct (ED). 


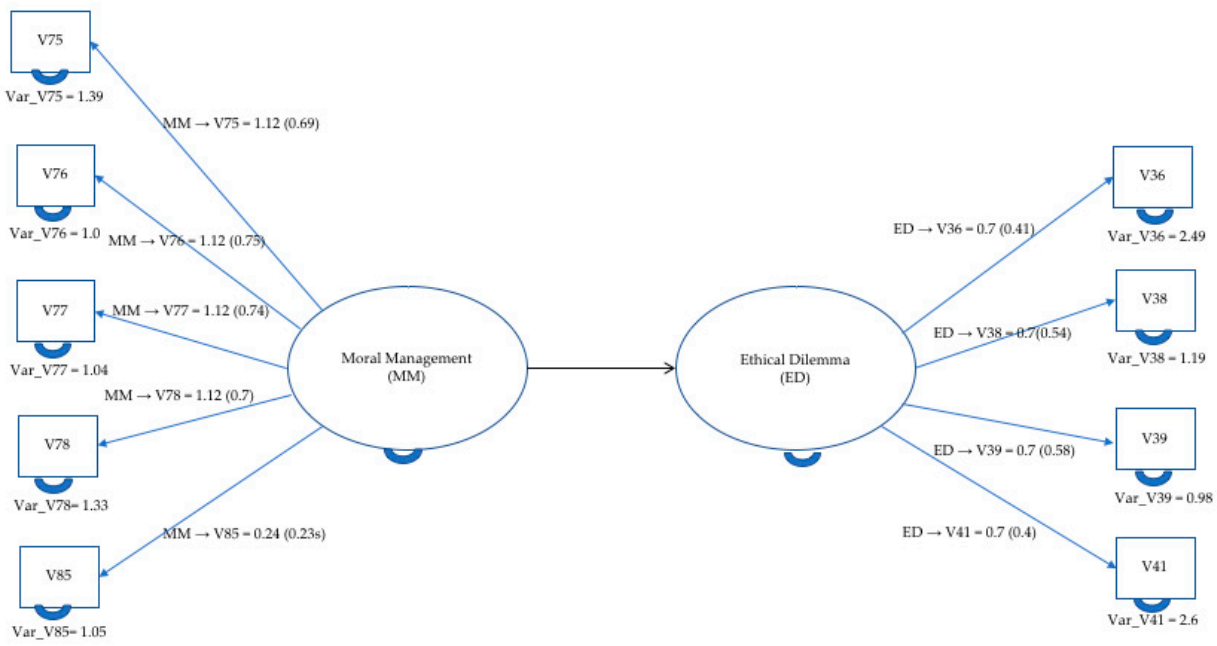

Figure 10. The third SEM model «explains» the relationship among the triggered «moral management» construct (MM) and the «ethical dilemma» construct (ED).

As for the first thought experiment (i.e., first moral model), the indicators «reflecting in» the «moral management» construct (i.e., V82,V84,V87) come from factor 4 of EFA. As said above, $V 84$ is an example of leadership request, since it recognizes the chief role played by «the example of the behavior of direct boss». V82 refers to a «the spread of markedly corporate culture». The fundamental role of both indicators is in line with the work of [38] and [39], according to whom, corporate culture plays a crucial role to uphold CSR and to increase the social value of corporations, while the CEO seems facilitating this relationship, in line with the role played by V84 indicator identified by the model in Figure 9. As said above, Carroll as well, in his work [11], pointed out the importance of the management in assuming a leadership position for his company or organization when ethical issues arise, as well as the chief role played by the cultural component.

Table 3 reports the analytical results showing the «goodness of the model» and its adequacy to explain the causal relationship among «moral management» and «ethical dilemma» constructs. As reported in the table, the scores of all the fundamental indices reach the highest admissible values (column of reference scores), thus supporting the plausibility of the model proposed in Figure 9.

Table 3. The table reports the goodness of the model represented in Figure 9. For each index, the corresponding reference scores (good and acceptable) is reported.

\begin{tabular}{cccc}
\hline Fit Index & Score & Good & Acceptable \\
\hline$\chi^{2} / \mathrm{df}$ & 0.954 & $0 \leq \chi^{2} / \mathrm{df} \leq 2$ & $2 \leq \chi^{2} / \mathrm{df} \leq 3$ \\
\hline CFI (Comparative fit index) & 0.991 & $0.97 \leq \mathrm{NFI} \leq 1.00$ & $0.95 \leq \mathrm{NFI} \leq 0.97$ \\
\hline TLI (The Tucker-Lewis coefficient) & 0.989 & As close as possible to 1 & \\
\hline $\begin{array}{c}\text { RMSEA (Root mean square error of } \\
\text { approximation) }\end{array}$ & 0.027 & $0 \leq$ RMSEA $\leq 0.05$ & $0.05 \leq$ RMSEA $\leq 0.10$ \\
\hline
\end{tabular}

It is interesting also noting the place occupied by the «moral management» construct of the model in Figure 9 in terms of Carroll's conceptual framework, since its indicators represent the «levers» that allow adopting high profile behaviors of the pyramid. As it was said, the indicators of this construct, as emerges from the EFA, in addition belonging to F4 (i.e., reputation and leadership tools), have in common the characteristic of representing «deliberate choices» of the management that, in other words, are not based on the adoption of protocols, certifications, law decrees or other written rules. If read in terms of attitudes, intentions, and 
beliefs, the «moral management» represents an intention (because it subsumes a kind of goal) of the management to adopt high standards when facing with conflict of values.

In the two thought experiments above, whose models are represented in Figures 8 and 9, both «immoral management» and «moral management» constructs are reflected in cultural levers (i.e., $V 28$ and $V 87$ ), but which are of different nature. In fact, in the first case, for example, the cultural «lever» is accompanied by the attitude to believe that the corruption phenomenon is a widespread practice (V24) and little has been done to combat corruption $(V 26)$. In the second thought experiment, however, that of Figure 9, the cultural «lever» is accompanied, among others, by the «example of the behavior of direct boss» (V84). The contextual importance of the presence of these two levers, culture and example of the direct boss, makes the contribution of the cultural aspects different from what happens for the first model, as also confirmed by the scientific literature. Reference [37] supported that corporate culture can come to life thanks to a founder, who elaborates and puts into practice particular concepts and values, such as, for example, a vision, a philosophy or a business strategy, guiding decision-making in the absence of written rules.

With the model of the next thought experiment, unlike the last one, the aim is evaluating the contribution of specific tools, of a «regulatory nature», at different levels, starting with the adoption of best practices at the corporate level (V85), to pass to any protocols and/or certifications (V77 and V78), up to the point of evaluating the specific contribution of law decrees (V76). Similar to what occurred for the model of Figure 9, the goal of the next thought experiment was to verify if these tools, on the whole, could have trigger a solution to the "ethical dilemma» as in the previous model, characterized by the emergence of attitude towards a «moral management» profile, the highest of Carroll's pyramid, marked by the motto «be a good corporate citizen», which captures the idea of philanthropic responsibility.

\section{Discussion}

Some aspects that emerged from the two levels of analysis offer interesting elements. In particular, the coherence between the attitude towards «moral management» and the Carroll's pyramid, the role of «socio-cultural» and «geographical» aspects in the adoption of anti-corruption behaviors and the relationship between «ethical certification» choices and ethical behaviors in the company. All of them are discussed in the following of this Section.

Factor 3 emerged from EFA finds its evidence in [40], which analyzed the role played by the board of directors with respect to the corruption prevention plans, to identify its role in the management of company's system, also considering the role of the «anti-corruption national legislation» (Law 190/2012) and the «risk management and organization model» (Legislative Decree 231/2001). Their investigation supports the idea that the board of directors has a central role in managing a company system and in the corporate corruption prevention, where it may play a chief role both for adopting and applying legislation [41].

An interesting aspect is offered by the importance of the social networks as perceived by respondents (Factor 4), proving to be a fundamental tool both for the diffusion of the corporate culture and its reputation.

Policies captured by factor 5 of EFA, fall within the third level of the pyramid of CSR. The adoption of sustainability policies, such as the «ethical certification SA 8000», is consistent with the work carried out by [42] that investigated the perception of «ethical certification SA 8000» in the landscape of Italian companies, showing that their adoption could improve both themselves with respect to external stakeholders and their own internal working environment. As can be seen from both Figure 5 and the Table 1, in addition to $S A 8000$ certification our findings also show the importance of other CSR tools and sustainable policies such as the D.L. 231/2011 on corporate responsibility, D.L. 190/2012 for public administrations, as showed also by [40] cited above (see Table 1).

Both factor 7 and factor 8 , if read contextually, denote an awareness of management, let's say a belief, according to which in the country are taking place bad practices, such as «corruption», in the relations between companies and public administration, and that explicitly refer to «socio-cultural» and «geographical» aspects. 
A high degree of adherence with these answers, that «reflect in» factor 10, can be interpreted as an attitude towards a «moral management» profile, the highest of Carroll's pyramid, according to which the company is expected to provide financial and human resources to the community, contributing to improve its quality of life as well.

Factor 2 and factor 10 represent two batteries of «ethical dilemmas» and, as such, they represent situations that arise when a choice, or a behavior, is desirable/undesirable due to potential positive/negative consequences of ethical nature. Factor 2 suggests an attitude that generates profits for the company, at the cost of paying a tribute in social and human terms, while factor 10 gives rise to variables that, unequivocally, recall the highest levels of the Carroll's pyramid.

Overall, the two factors represent the outputs of two possible «codes of conduct», respectively an «unethical management» and an «ethical management», that are triggered depending on certain circumstances (i.e., variables/responses). The topic is covered in the following of this discussion, where these «codes of conduct» presented in the light of simulations through thought experiments which, in turn, are modeled through SEM, as shown in Section 4.

As with regards the «moral management» construct for the model in Figure 10 (i.e., second moral model), as can be seen, it is reflected in five indicators that are characterized by a general intention to implement «legislative measures» (V76), «ethical rules» (V78), and protocols (V77), as emerged from EFA above. Sustainability policies, such as the «ethical certification SA 8000», is consistent with the work carried out by [30], which showed how companies adopted this standard in order to increase their relations with external stakeholders and with the internal working environment. From EFA also emerged the importance of other CSR tools and sustainable policies such as the D.L. 231/2011 on corporate responsibility and D.L. 190/2012 for public administrations, whose relevance is also highlighted by the literature [40]. The model proposed in Figure 10 analyzes the contextual contribution of these tools, whereas the literature, up to now, investigated looking at their role individually.

Other two indicators «reflect in» the moral management construct of Figure 10, that are $V 75$, representing the board of directors, and $V 85$ that represents any organization action to spread the culture of ethics. As regarding the former, [40] showed its chief role in both for adopting and applying legislation, also considering the role of the anti-corruption national legislation (Law 190/2012) and the risk management and organization model (Legislative Decree 231/2001). Last, but not least, it was also hypothesized if the "moral management» construct could also be «reflected in» the V85 indicator which, for all effects, seems to be a tool capable of promoting the coexistence, the implementation and effectiveness of the other indicators described above.

Table 4 reports the "goodness of the model» represented in Figure 10. Analytical results show its plausibility for explaining the causal relationship among «moral management» and «ethical dilemma» constructs, since the scores of all the fundamental indices reach the highest admissible values (column of reference scores).

Similar to the thought experiment represented by the model in Figure 9, also the model of Figure 10 solves the "ethical dilemma» adopting behaviors that occupy the highest level of Carroll's pyramid. However, the causes of these desirable actions are not «deliberate choices» of a management, as in the previous model, but codified sustainable policies that are favored by a board of directors directly involved in their implementation and by specific corporate implementation actions.

On the whole, thought experiments reproduced in the models of Figures 9 and 10 show that there is the possibility of adopting ethical behaviors on the part of management and that if such behaviors are not deliberate, such as in the model of Figure 9, there is the possibility of «stimulating» them by resorting to adequate adoption of sustainable policies, as supported by the model of Figure 10. 
Table 4. The table reports the goodness of the model represented in Figure 10. For each index, the corresponding reference scores (good and acceptable) is reported.

\begin{tabular}{cccc}
\hline Fit Index & Score & \multicolumn{2}{c}{ Reference Scores } \\
\hline$\chi^{2} / \mathrm{df}$ & 1.157 & $0 \leq \chi^{2} / \mathrm{df} \leq 2$ & Acceptable \\
\hline CFI (Comparative fit index) & 0.96 & $0.97 \leq \mathrm{NFI} \leq 1.00$ & $0.95 \leq \mathrm{NFI} \leq 0.97$ \\
\hline TLI (The Tucker-Lewis coefficient) & 0.956 & As close as possible to 1 & \\
\hline $\begin{array}{c}\text { RMSEA (Root mean square error of } \\
\text { approximation) }\end{array}$ & 0.044 & $0 \leq$ RMSEA $\leq 0.05$ & $0.05 \leq$ RMSEA $\leq 0.10$ \\
\hline
\end{tabular}

\section{Conclusions}

Decision makers are aware of the importance of corporate social responsibility and ethical choices within the strategic business vision. However, the number of tools, levers, and rules available (e.g., board of directors, social example of direct boss, or law decrees) makes it difficult for management to identify the set of best practices to be adopted within its own organization.

The paper reports on the analysis of a survey whose data have been modelled through "Carroll's conceptual framework», that is made of the CSR pyramid and the descriptive types of management, employing a two steps multivariate analysis. First, an Exploratory Factor Analysis (EFA) has been used to identify Carroll's descriptive types (or profiles). From EFA emerges an attitude and a general intention towards «moral management». This preliminary analysis also supports the chief role played by «reputation» and «leadership» factors within an organization. Other factors emerged from EFA, clearly represent a "container» of CSR tools and policies, or somehow that have familiarity with reputation and leadership.

Subsequently, the research interest focused on the role that some tools (e.g., «reputation» and «leadership»), and levers («cultural» and «social»), could play in the choices of management, so that it could orient itself in «conduct» worthy of the upper part of the Carroll pyramid. To answer this type of question three simulations of the thought experiments conducted by means of Structural Equation Modelling (SEM) have been performed. In other words, SEMs were employed to verify the plausibility of the causal models that represent, in turn, thought experiments simulating «ethical dilemmas» useful for the company's management during its decision making.

With the first thought experiment, the model states that when an «ethical dilemma» arises, the management probably will adopt unethical behaviors when these are believed useful for the company, as expected by the lowest level of Carroll pyramid.

For the second thought experiment the model also confirms what supported by a body of knowledge, according to, when an ethical dilemma arises, if the appropriate social (i.e., reputational) and cultural conditions exist, the manager succeeds in assuming a leadership position for his company [16-19].

Finally, the third thought experiment: it has been tested the role played by specific sustainability policies, such as the «ethical certification SA 8000», legislative Decrees 231/2011 on corporate responsibility and D.L. 190/2012 for public administrations, besides indicators representing tools such as the board of directors and organization action to spread the culture of ethics. The "ethical certification SA 8000» is consistent with the work carried out by [42]. As regarding the board of directors, [40] showed its chief role in both for adopting and applying legislation, also considering the role of the anti-corruption national legislation (Law 190/2012) and the risk management and organization model (Legislative Decree 231/2001). On the whole, the third model proposed an analysis to evaluate the contextual contribution of these tools, whereas in the literature their role has been investigated looking at their role individually.

On the whole, thought experiments reproduced in the two «moral management» models show that, on the part of management, there is the possibility of adopting ethical behaviors 
and that if such behaviors are not «deliberate», there is the possibility of encouraging them by resorting to adequate adoption of sustainable policies.

The results of this investigation can have some practical implications, as, for instance, become the subject of specific training programs at company and organizational level, especially for new hires. The models, in fact, are easily viewable and disseminated even with the new Human Resources (HR) employed within the organization. In addition, HR units can commit the results of both the EFA and the SEMs. The former to identify possible risk profiles (i.e., immoral or moral manager) within the organization, while the latter, in the form of «ethical dilemmas», can be useful to understand and establish the management's orientation in certain situations and, obviously, to guess what their orientation would be with respect to specific sustainability policies, adopted or to be adopted within the organization. Finally, since the models identified in the research are easy to understand, any type of organization, even of a small size, interested in adopting sustainable policies, can make use of the above models to establish, pragmatically, both «deliberate» and «regulated» guidelines to be employed.

This investigation presents some limitations that have to be addressed in the future. For instance, from EFA emerged the «lobbying» indicator according to «the regulated and transparent lobbying activity can be positive [ ... ]». This is in line with [37], which support that «business lobbying is a socially responsible activity which needs to be restrained by ethical standards». SEMs, however, did not identify any role for this indicator, in none of the three thought experiments. Given the enormous debate that has emerged in Italy in recent years on the role of lobbying, we hope to address this issue in a future experimentation where, perhaps, a greater number of responses will allow the attribution of a direct or mediating role to lobbying.

Another limitation of this work emerges when considering the results «reflecting in» variables/responses that explicitly refer to «socio-cultural» and «geographical» aspects. Their role needs a more focused analysis in the light of other specific indicators emerged from EFA according to «corruption» is «linked to the culture of a country» and «does not have a strictly economic root».

Author Contributions: Conceptualization, E.D., M.F. and E.B.; methodology, E.D.; software, E.D.; validation, E.B. and M.F.; formal analysis, E.D.; investigation, E.B. and E.D.; resources, E.B.; data curation, E.D.; writing—original draft preparation, E.D., M.F. and E.B.; writing—review and editing, E.D., M.F. and E.B.; visualization, E.D.; supervision, E.B.; project administration, E.B.; funding acquisition, E.B. All authors have read and agreed to the published version of the manuscript.

Funding: This research received no external funding.

Institutional Review Board Statement: Not applicable.

Informed Consent Statement: Not applicable.

Data Availability Statement: Data can be requested from the authors of the paper.

Conflicts of Interest: The authors declare no conflict of interest.

\section{References}

1. Sheehy, B. Defining CSR: Problems and Solutions. J. Bus. Ethics 2015, 131, 625-648. [CrossRef]

2. Liang, H.; Renneboog, L. On the Foundations of Corporate Social Responsibility. J. Financ. 2017, 72, 853-910. [CrossRef]

3. Matten, D.; Moon, J. Corporate Social Responsibility. J. Bus. Ethics 2004, 54, 323-337. [CrossRef]

4. McGuire, J.B.; Sundgren, A.; Schneeweis, T. Corporate Social Responsibility and Firm Financial Performance. Acad. Manag. J. 1988, 31, 854-872. [CrossRef]

5. Carroll, A.B. Corporate Social Responsibility: Evolution of a Definitional Construct. Bus. Soc. 1999, 38, 268-295. [CrossRef]

6. Garriga, E.; Mele, D. Corporate Social Responsibility Theories: Mapping the Territory. J. Bus. Ethics 2004, 53, 51-71. [CrossRef]

7. Freundlieb, M.; Teuteberg, F. Corporate social responsibility reporting-A transnational analysis of online corporate social responsibility reports by market-listed companies: Contents and their evolution. Int. J. Innov. Sustain. Dev. 2013, 7, 1-26. [CrossRef]

8. Etter, M.; Fieseler, C.; Whelan, G. Sharing Economy, Sharing Responsibility? Corporate Social Responsibility in the Digital Age. J. Bus. Ethics 2019, 159, 935-942. [CrossRef] 
9. Yuan, Y.; Lu, L.Y.; Tian, G. Business Strategy and Corporate Social Responsibility. J. Bus. Ethics 2020, 162, 359-377. [CrossRef]

10. Masini, C. Lavoro e Risparmio; UTET: Torino, Italy, 1979.

11. Carroll, A.B. The pyramid of corporate social responsibility: Toward the moral management of organizational stakeholders. Bus. Horiz. 1991, 34, 39-48. [CrossRef]

12. Schwartz, M.; Carroll, A. Corporate Social Responsibility: A Three-Domain Approach. Bus. Ethics Q. 2003, 13, 503-530. [CrossRef]

13. Meynhardt, T.; Gomez, P. Building Blocks for Alternative Four-Dimensional Pyramids of Corporate Social Responsibilities. Bus. Soc. 2019, 58, 404-438. [CrossRef]

14. Simon, H.S. Invariants of Human Behavior. Annu. Rev. Psychol. 1990, 41, 1-20. [CrossRef]

15. Hart, S.M. Self-regulation, Corporate Social Responsibility, and the Business Case: Do they Work in Achieving Workplace Equality and Safety? J. Bus. Ethics 2010, 92, 585-600. [CrossRef]

16. Carlson, D.S.; Perrewe, P.L. Institutionalization of organizational ethics through transformational leadership. J. Bus. Ethics 1995, 14, 829-838. [CrossRef]

17. Mihelic, K.K.; Lipicnik, B.; Tekavcic, M. Ethical Leadership. Int. J. Manag. Inf. Syst. 2010, 14, 31-34. [CrossRef]

18. Kaptein, M. The Moral Entrepreneur: A New Component of Ethical Leadership. J. Bus. Ethics 2019, 156, 1135-1150. [CrossRef]

19. Carroll, A.B. Ethical Challenges for Business in the New Millennium: Corporate Social Responsibility and Models of Management Morality. Bus. Ethics Q. 2000, 10, 33-42. [CrossRef]

20. Baden, D. A reconstruction of Carroll's pyramid of corporate social responsibility for the 21st century. Int. J. Corporate Soc. Responsib. 2016, 1, 8. [CrossRef]

21. Masoud, N. How to win the battle of ideas in corporate social responsibility: The International Pyramid Model of CSR. Int. J. Corp. Soc. Responsib. 2017, 2, 4. [CrossRef]

22. Lu, J.; Ren, L.; Zhang, C.; Rong, D.; Ahmed, R.R.; Streimikis, J. Modified Carroll's pyramid of corporate social responsibility to enhance organizational performance of SMEs industry. J. Clean. Prod. 2020, 217, 122456. [CrossRef]

23. Carroll, A.B. Carroll's pyramid of CSR: Taking another look. Int. J. Corp. Soc. Responsib. 2016, 34, 39-48. [CrossRef]

24. Visser, W. The Age of Responsibility: CSR 2.0 and the New DNA of Business; John Wiley \& Sons: West Sussex, UK, 2011.

25. Norris, M.; Lecavalier, L. Evaluating the Use of Exploratory Factor Analysis in Developmental Disability Psychological Research. J. Autism Dev. Disord. 2010, 40, 8-20. [CrossRef] [PubMed]

26. Field, A. Discovering Statistics Using SPSS for Windows. Advanced Techniques for Beginners; Sage Publications: Thousand Oak, CA, USA, 2000.

27. Agarwal, J.; Malloy, D.C. Ethical Work Climate Dimensions in a Not-For-Profit Organization: An Empirical Study. J. Bus. Ethics 1999, 20, 1-14. [CrossRef]

28. Patil, V.H.; Singh, S.N.; Mishra, S.; Donavan, D.T. Efficient theory development and factor retention criteria: Abandon the 'eigenvalue greater than one' criterion. J. Bus. Res. 2008, 61, 162-170. [CrossRef]

29. Ruscio, J.; Roche, B. Determining the number of factors to retain in an exploratory factor analysis using comparison data of known factorial structure. Psychol. Assess. 2012, 24, 282-292. [CrossRef]

30. Rietveld, T.; Van Hout, R. Statistical Techniques for the Study of Language and Language Behaviour; Mouton de Gruyter: Berlin, Germany; New York, NY, USA, 1993.

31. Reio, T.G.; Shuck, B. Exploratory Factor Analysis: Implications for Theory, Research, and Practice. Adv. Dev. Hum. Resour. 2015, 17, 12-25. [CrossRef]

32. Iantovics, L.B.; Rotar, C.; Morar, F. Survey on establishing the optimal number of factors in exploratory factor analysis applied to data mining. WIREs Data Min. Knowl. Discov. 2019, 9, e1294. [CrossRef]

33. Khan, N.U.; Wu, W.; Saufi, R.B.A.; Sabri, N.A.A.; Shah, A.A. Antecedents of Sustainable Performance in Manufacturing Organizations: A Structural Equation Modeling Approach. Sustainability 2021, 13, 897. [CrossRef]

34. Stevens, J.P. Applied Multivariate Statistics for the Social Sciences, 2nd ed.; Lawrence Erlbaum Associates: Mahwah, NJ, USA, 1992.

35. Revelle, W.; Rocklin, T. Very Simple Structure: An Alternative Procedure for Estimating the Optimal Number of Interpretable Factors. Multivar. Behav. Res. 1979, 14, 403-414. [CrossRef] [PubMed]

36. Kyriazos, T. Applied Psychometrics: Sample Size and Sample Power Considerations in Factor Analysis (EFA, CFA) and SEM in General. Psychology 2018, 9, 2207-2230. [CrossRef]

37. Hamilton, J.; Hoch, D. Ethical Standards for Business Lobbying: Some Practical Suggestions. Bus. Ethics Q. 1997, 7, 117-129. [CrossRef]

38. Maak, T. Undivided Corporate Responsibility: Towards a Theory of Corporate Integrity. J. Bus. Ethics 2008, 82, 353-368. [CrossRef]

39. Remišová, A.; Lašáková, A.; Kirchmayer, Z. Influence of Formal Ethics Program Components on Managerial Ethical Behavior. J. Bus. Ethics 2019, 160, 151-166. [CrossRef]

40. Lombardi, L.; Trequattrini, R.; Cuozzo, B.; Cano-Rubio, M. Corporate corruption prevention, sustainable governance and legislation: First exploratory evidence from the Italian scenario. J. Clean. Prod. 2019, 217, 666-675. [CrossRef]

41. Băndoi, A.; Bocean, C.G.; Del Baldo, M.; Mandache, L.; Mănescu, L.G.; Sitnikov, C.S. Including Sustainable Reporting Practices in Corporate Management Reports: Assessing the Impact of Transparency on Economic Performance. Sustainability 2021, 13, 940. [CrossRef]

42. Murmura, F.; Bravi, L.; Palazzi, F. Evaluating companies' commitment to corporate social responsibility: Perceptions of the SA 8000 standard. J. Clean. Prod. 2017, 164, 1406-1418. [CrossRef] 